\title{
Multi-criteria optimization in terms of fuzzy criteria definitions
}

\author{
Raskin L., Sira O., Sagaydachny D. \\ National Technical University "Kharkiv Polytechnic Institute", \\ 2 Kyrpychov Str., Kharkiv, 61002, Ukraine
}

(Received 5 December 2018)

\begin{abstract}
The problems of multi-criteria optimization are considered. Known methods for solving these problems are generalized to the case when weights that take into account the relative importance of particular criteria are not clearly defined. The procedure for constructing membership functions of fuzzy numbers, given by sets of intervals of possible values, using a linearized computation of least squares methods is substantiated. In this case, for the description of fuzzy numbers, the membership functions of (L-R)-type were chosen.

A method for solving a fuzzy multi-criteria optimization problem for a scalarized criterion is proposed. The technology of solving the problem reduces it to a linear fractional problem of mathematical programming. A converging iterative procedure for finding the optimal plan is described.

An alternative method for solving the original fuzzy problem based on the formation of a Pareto-set of non-dominated options is considered. To solve this problem, a procedure has been proposed for comparing fuzzy numbers using a probability-theoretic approximation of their membership functions.
\end{abstract}

Keywords: multi-criteria optimization, fuzzy source data, optimization of a fractional non-linear functional, Pareto-set.

2000 MSC: $90 \mathrm{~B} 99$

UDC: 519.856 .2

DOI: $10.23939 / \mathrm{mmc} 2018.02 .207$

\section{Introduction}

An essential component of the set of tasks solved in the design of real systems is the evaluation of the effectiveness of their functioning according to a variety of criteria. The numerical values of these criteria depend on a set of parameters defining the structure, as well as technical, technological and other properties of the system and the process of its operation. In accordance with this, let us introduce the set $B=\left(b_{1}, b_{2}, \ldots, b_{s}\right)$ of parameters and the set $\Phi=\left(\Phi_{1}(B), \Phi_{2}(B), \ldots, \Phi_{k}(B), \ldots, \Phi_{n}(B)\right)$ of system criteria.

Now the design problem can be formulated as the following multi-criteria mathematical programming problem: find the set $B=\left(b_{1}, b_{2}, \ldots, b_{s}\right)$ that delivers extreme values to criteria on the set $\Phi_{1}(B), \Phi_{2}(B), \ldots, \Phi_{n}(B)$ of admissible values. It is clear that such a task does not necessarily have a solution (as a rule, such a set B does not exist). Therefore, there arises a specific problem of criteria harmonization, the difficulty of solving which is determined primarily by the contradictory nature of the system requirements set by various criteria. 


\section{Analysis of traditional multi-criteria optimization methods}

Let us analyze the possible approaches to solving the problem of multi-criteria (vector) optimization. Let for definiteness all criteria be minimized.

\section{Scalarization of a vector criterion by the introduction of a linear combination of} criteria.

In this case, the vector criterion $\Phi_{1}(B), \Phi_{2}(B), \ldots, \Phi_{n}(B)$ is additively converted to scalar as follows:

$$
\Phi_{\Sigma}(B)=\sum_{j=1}^{n} a_{j} \Phi_{j}(B) \Rightarrow \min _{B},
$$

where $a_{i}$ is the weight coefficient taking into account the importance of the criterion.

2. Scalarization of a vector criterion by forming a product of quotients.

In this case, as an analogue (1), the following is introduced:

$$
\Phi_{\Pi}(B)=\prod_{j=1}^{m}\left(\Phi_{j}(B)\right)^{a_{j}} .
$$

The disadvantage of this approach is as follows. Let each of the criteria be, for example, the probability of the implementation of a property in a system (cost, resistance to external disturbances, etc.) or the probability of solving a particular task facing the system. Then $\Phi_{j}(B) \in[0,1], j=$ $1,2, \ldots, n$. In this case, it is clear that the minimum of the criteria $\Phi_{j_{0}}(B)=\min _{j} \Phi_{j}(B)$ majorizes the product, that is $\Phi_{\Pi}(B)<\Phi_{j_{0}}(B)$. If $\Phi_{j_{0}}(B)$ is not enough, the criterion $\Phi_{\Pi}(B)$ becomes weakly sensitive to changes in all its components.

3. Assessment of proximity to the "ideal" system.

When implementing this approach, first for each of the particular criteria determine its best, "ideal" value, i.e.,

$$
\Phi_{j}^{*}=\underset{B \in G}{\operatorname{extr}} \Phi_{j}(B), \quad i=1,2, \ldots, n .
$$

Now, to assess the degree of closeness of a real system, the efficiency and quality of which is given by a set of numbers $\Phi_{1}(B), \Phi_{2}(B), \ldots, \Phi_{n}(B)$, let us introduce

$$
\Phi_{\Pi}(B)=\sum_{j=1}^{n} \alpha_{i}\left(\Phi_{j}^{*}-\Phi_{j}(B)\right)^{2} .
$$

Let us point out the general lack of composite criteria of the type (1)-(3). When optimizing for these criteria, it may turn out that the unacceptably small values of one or several partial criteria correspond to the optimal solution from the point of view of a composite scalar criterion.

\section{Joint optimization by several criteria (Pareto-optimization).}

Let in $n$-dimensional criterion space $\Phi_{1}(B), \Phi_{2}(B), \ldots, \Phi_{n}(B)$, be given a certain number of points corresponding to different results of solving a multi-criteria problem. Let us assume that the point $B^{\prime}$ is not worse than the point $B$ if

$$
\Phi_{j}\left(B^{\prime}\right) \leqslant \Phi_{j}(B), \quad j=1,2, \ldots, n,
$$

and the point $B^{\prime}$ is better than the point $B$ if at least one of the inequalities (4) is strictly satisfied. Let us assume that the point $B$ is effective if there is no the point $B^{\prime} \in G$ better than $B$. If such the point $B^{\prime}$ exists, then the point $B$ is ineffective. Now the optimal option of building a system is chosen from the set of effective (Pareto-set). The best of the Pareto-set of effective options is selected on the basis of any additional considerations. This choice can be made, for example, as follows. Let us consider a problem in which different options of building a system are compared to each other 
according to two standardized criteria $\Phi_{1} \in[0,1], \Phi_{2} \in[0,1]$. These options are represented by dots in the two-dimensional space $\left(\Phi_{1}, \Phi_{2}\right)$ presented in Fig. 1.

In this case, the options $B_{1}, B_{2}, B_{3}$ form a

Pareto-set of effective options. Comparison of options $B_{1}$ and $B_{2}$ shows that the option $B_{2}$ is better than the option $B_{1}$ by the criterion $\Phi_{1}$ by the value $\Delta \Phi_{12}^{(1)}$, but worse by the value $\Delta \Phi_{12}^{(2)}$ by the criterion $\Phi_{2}$. If $\eta_{12}=\frac{\Delta \Phi_{12}^{(1)}}{\Delta \Phi_{12}^{(2)}}>1$, then $B_{2}$ is preferable $B_{1}$. Further, even from the comparison $B_{3}$ and $B_{2}$ it is clear that $B_{3}$ is better $B_{2}$ by the value $\Delta \Phi_{23}^{(1)}$ by the criterion $\Phi_{1}$, but worse by the value $\Delta \Phi_{23}^{(2)}$ by the criterion $\Phi_{2}$. If $\eta_{23}=\frac{\Delta \Phi_{23}^{(1)}}{\Delta \Phi_{23}^{(2)}}<1$, then the option

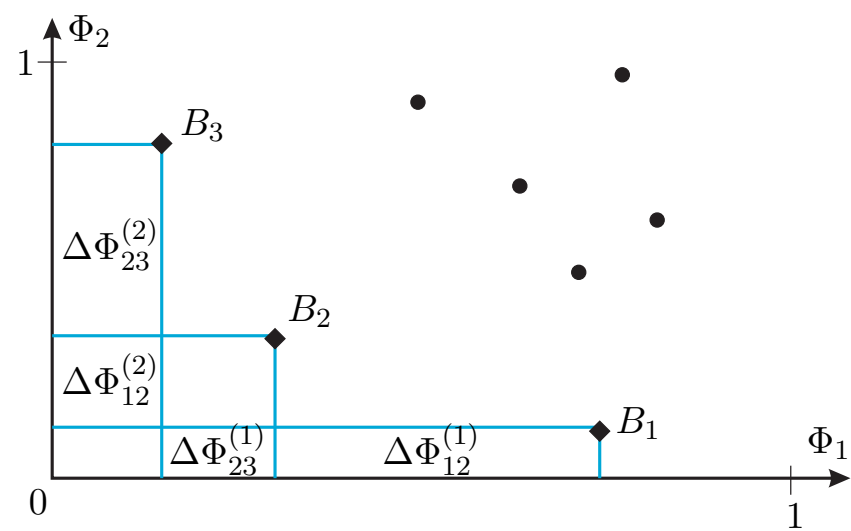

Fig. 1. Pareto-set of options in space $\left(\Phi_{1}, \Phi_{2}\right)$. $B_{2}$ is preferable than $B_{3}$. Thus, it turns out that the option $B_{2}$ is preferable than $B_{1}$ and $B_{3}$. It should be chosen. The natural enhancement of this idea is to use weights $\alpha_{i}, i=1,2, \ldots, m$, taking into account the differences in the importance of the criteria. At the same time for a couple of options $B_{j 1}$ and $B_{j 2}$ a measure of preference should be calculated by the formula $\eta_{j_{1} j_{2}}=\frac{\alpha_{1} \Delta \Phi_{j_{1} j_{2}}^{(1)}}{\alpha_{2} \Delta \Phi_{j_{1} j_{2}}^{(2)}}>1$.

\section{The selection of the decisive criterion.}

In this case, from the totality of criteria $\Phi_{1}(B), \Phi_{2}(B), \ldots, \Phi_{m}(B)$, choose one $\Phi_{j_{0}}(B)$, the most important. For all other criteria $j \neq j_{0}$, the threshold value $d_{i}$ is set. Now the problem of multi-criteria optimization is transformed into a normal optimization problem on a conditional extremum: find

$$
B^{*}=\underset{B \in G(B)}{\arg \operatorname{extr}} \Phi_{j_{0}}(B),
$$

where

$$
G(B)=\left\{B: \Phi_{j}(B) \leqslant d_{j}, j \neq j_{0}\right\} .
$$

Some possible enhancement of this approach is associated with the introduction of "concessions". In this case, it is assumed that relatively small changes in the threshold values of the criteria that form the permissible domain, "concessions", can lead to a significant improvement in the value of the criterion by which optimization is carried out. Thus, let us arrive at a problem in which the numerical value of the criteria - constraints are imposed on two-sided constraints of the form

$$
d_{j} \min \leqslant \Phi_{j}(B) \leqslant d_{j} \max ,
$$

where $\left[d_{j} \min , d_{j} \max \right]$ is the allowable range of the $j$-th criterion value. In this case, there is a significant expansion of the area of possible solutions $G$, which naturally provides the possibility of obtaining a better solution according to the main criterion $\Phi_{j_{0}}(B)$. The resulting problem (5)-(6) is a general problem of mathematical programming.

It is clear that the result of solving multi-criteria tasks depends on how the set of weights is chosen. In accordance with this, the GOAL of the conducted research is development of a method for solving multi-criteria optimization problems, taking into account differences in the importance of criteria.

\section{Development of multi-criteria optimization method}

To accomplish this goal it is necessary to solve the following tasks: 1) development of a technology for assessing the importance of criteria; 2) development of a method for solving multi-criteria optimization problems, taking into account the uncertainty that arises when assessing the importance of criteria. 
Let us proceed to the consideration of the tasks.

The numerical values of the coefficients $a_{j}, j=1,2, \ldots, n$, taking into account the relative importance of particular criteria, are independently evaluated by a group of experts. Each expert $k$, $k=1,2, \ldots, m$ for each pair of criteria $\Phi_{j_{1}}, \Phi_{j_{2}}$ sets a number $W_{k j_{1} j_{2}}$ that determines the level of preference $\Phi_{j_{1}}$ of the criterion $\Phi_{j_{1}}$ in comparison with $\Phi_{j_{2}}, j_{1}=1,2, \ldots, n, j_{2}=1,2, \ldots, n$. In this case, matrices $\left(W_{k j_{1} j_{2}}\right)$ are formed, which are averaged over $k$. As a result, an inversely symmetric matrix $\left(W_{j_{1} j_{2}}\right)$ of pairwise comparisons of the importance of the criteria is determined [1]. If this matrix is consistent, i.e., for all $j_{1}=1,2, \ldots, n, j_{2}=1,2, \ldots, n, j_{k}=1,2, \ldots, n$ the equality is satisfied $W_{j_{1} j_{2}}=W_{j_{1} j_{k}} W_{j_{k} j_{2}}$, then it can be used to directly calculate the importance of criteria $a_{j}$, $j=1,2, \ldots, n$, according to the formula [2]

$$
a_{j_{1}}=\frac{\sum_{j_{2}=1}^{n} W_{j_{1} j_{2}}}{\sum_{j_{1}=1}^{n} \sum_{j_{2}=1}^{n} W_{j_{1} j_{2}}}, \quad j_{1}=1,2, \ldots, n .
$$

The situation becomes more complicated if, in view of the difficulty of forming a matrix of pairwise comparisons of the importance of criteria, each expert $k, k=1,2, \ldots, m$ for each criterion, for example $\Phi_{j}$, sets the interval $\left[a_{j k}^{(1)}, a_{j k}^{(2)}\right]$ of the set of possible values of importance $\alpha_{j}$.

The obtained set of intervals $\left\{\left[a_{j k}^{(1)}, a_{j k}^{(2)}\right]\right\}, k=1,2, \ldots, m$ is statistically processed. Let this set, defined, for example, by five experts, for the specific criterion $\Phi_{j}$, be of the form presented in Fig. 2 .

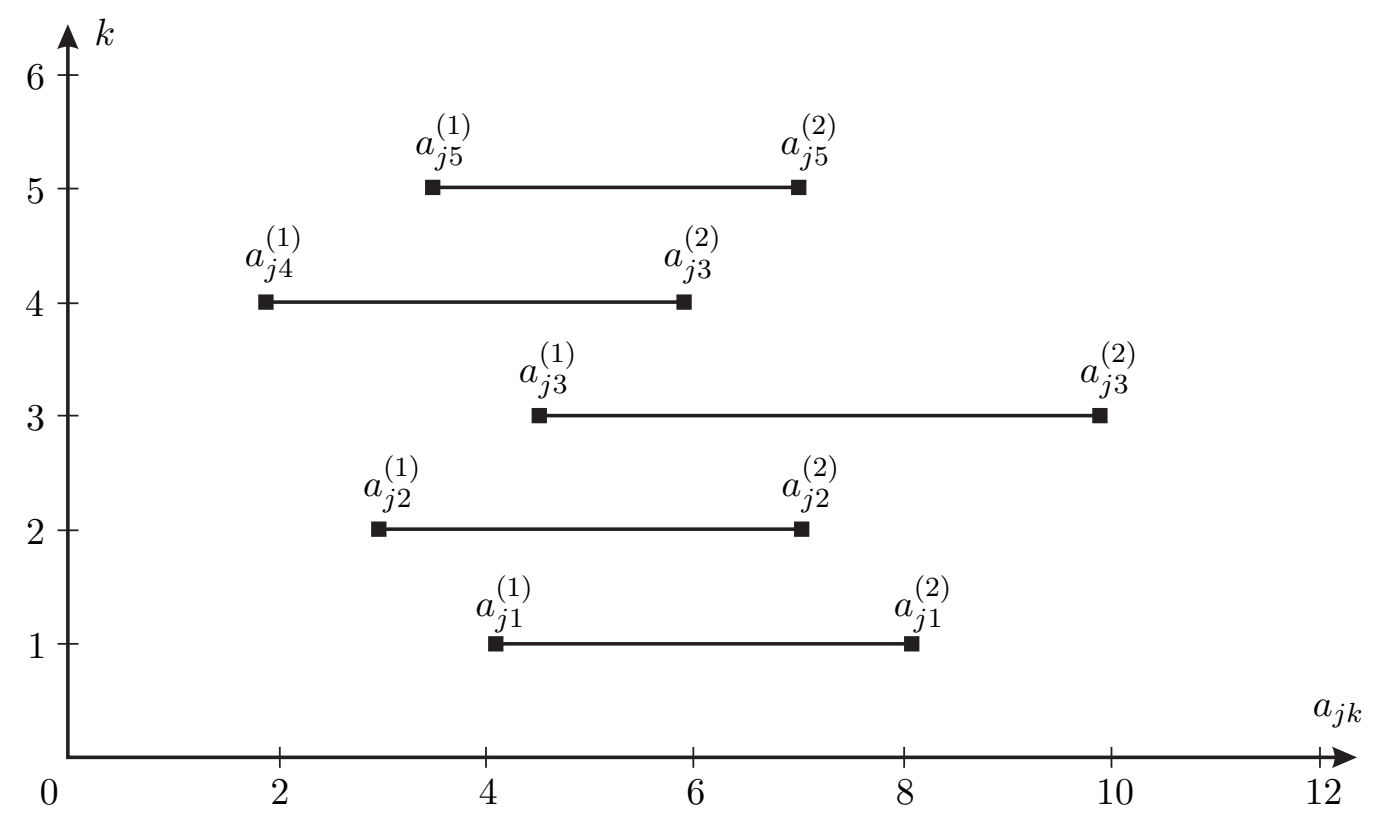

Fig. 2. A set of intervals that determine the importance of the criterion $\Phi_{j}$.

Let us determine the minimal and maximal possible values of the indicator $a_{j}$ :

$$
a_{j \min }=\min _{k}\left\{a_{j k}^{(1)}\right\}, \quad a_{j \min }=\max _{k}\left\{a_{j k}^{(2)}\right\} .
$$

Now for each value $a_{j} \in\left[a_{j \min }, a_{j \max }\right]$ let us determine the number

$$
\eta_{j k}\left(a_{j}\right)= \begin{cases}1, & \text { if } a_{j} \in\left[a_{j k}^{(1)}, a_{j k}^{(2)}\right] \\ 0, & \text { otherwise }\end{cases}
$$


Next, for the indicator $a_{j}$, let us define a piecewise constant function

$$
\kappa_{j}\left(a_{j}\right)=\sum_{k=1}^{m} \eta_{j k}\left(a_{j}\right)
$$

In this case, in the situation shown in Fig. 2, this function will have the form shown in Fig. 3.

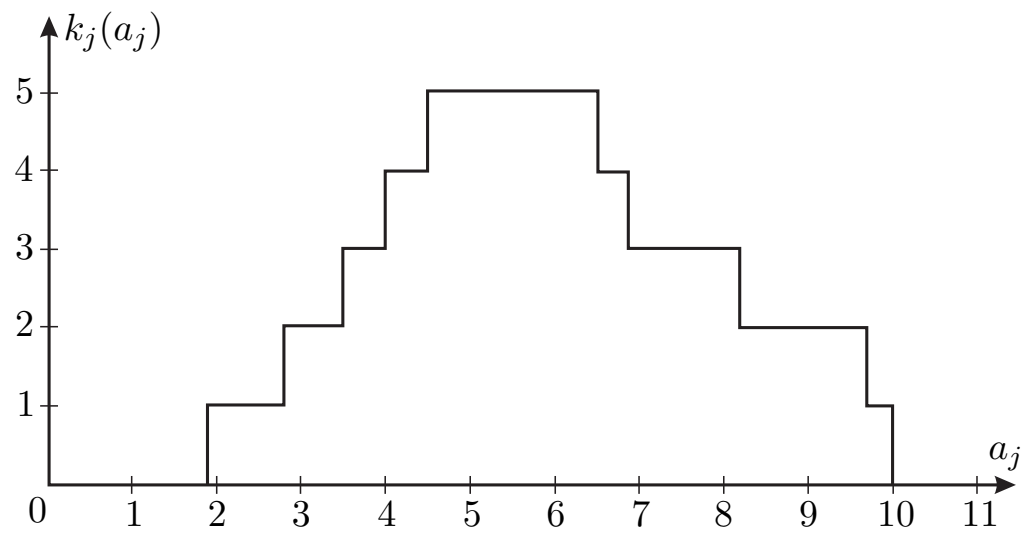

Fig. 3. Function $\kappa_{\mathrm{j}}\left(a_{j}\right)$.

The resulting uncertainty about the value $a_{j}$ is not completely correct to describe in terms of probability theory due to the small sample size of the source data. Information less demanding approach can be implemented using the mathematics of fuzzy sets [3-5]. In this regard, considering $a_{j}$ a fuzzy number, let us introduce for its description the membership function (L-R)-of the type:

$$
\mu_{j}\left(a_{j}\right)= \begin{cases}L\left(\frac{m_{j}^{(1)}-a_{j}}{\alpha_{j}}\right), & a_{j} \leqslant m_{j}^{(1)}, \\ 1, & m_{j}^{(1)}<a_{j}<m_{j}^{(2)}, \\ R\left(\frac{a_{j}-m_{j}^{(2)}}{\beta_{j}}\right), & a_{j} \geqslant m_{j}^{(2)},\end{cases}
$$

where $\left[m_{j}^{(1)}, m_{j}^{(2)}\right]$ is a core of a fuzzy number $a_{j}, \alpha_{j}, \beta_{j}$ are left and right fuzziness coefficients.

To estimate the values of the parameters, $m_{j}^{(1)}, m_{j}^{(2)}, \alpha_{j}, \beta_{j}$ let us introduce the tables $\left\{a_{j s}^{(1)}, \hat{\kappa}\left(a_{j s}^{(1)}\right)\right\}$, $\left\{a_{j s}^{(2)}, \hat{\kappa}\left(a_{j s}^{(2)}\right)\right\}$, defining the left and right branches of the membership function (8). Here $\hat{\kappa}\left(a_{j s}^{(1)}\right)=$ $\frac{\kappa\left(a_{j s}^{(1)}\right)}{\max \kappa\left(a_{j s}^{(1)}\right)}, \hat{\kappa}\left(a_{j s}^{(2)}\right)=\frac{\kappa\left(a_{j s}^{(2)}\right)}{\max \kappa\left(a_{j s}^{(2)}\right)}$. In this example, these tables have the following form.

Table 1. Description of the left branch $\kappa_{j}\left(a_{j}\right)$.

\begin{tabular}{|c|c|c|c|c|c|}
\hline$a_{j s}^{(1)}$ & $1.7-2.8$ & $2.8-3.5$ & $3.5-4.0$ & $4.0-4.5$ & $4.5-5.4$ \\
\hline$\hat{\kappa}\left(a_{j s}^{(1)}\right)$ & 0.2 & 0.4 & 0.6 & 0.8 & 1.0 \\
\hline
\end{tabular}

Table 2. Description of the left branch $\kappa_{j}\left(a_{j}\right)$.

\begin{tabular}{|c|c|c|c|c|c|}
\hline$a_{j s}^{(2)}$ & $5.4-6.5$ & $6.5-6.9$ & $6.9-8.2$ & $8.2-9.7$ & 9.7 \\
\hline$\hat{\kappa}\left(a_{j s}^{2}\right)$ & 1 & 0.8 & 0.6 & 0.4 & 0.2 \\
\hline
\end{tabular}


For an analytical description of the membership function (8), let us use the Gaussian representation:

$$
L\left(\frac{m_{j}^{(1)}-a_{j}}{\alpha_{j}}\right)=\exp \left\{-\left(\frac{m_{j}^{(1)}-a_{j}}{\alpha_{j}}\right)^{2}\right\}, \quad R\left(\frac{a_{j}-m_{j}^{(2)}}{\beta_{j}}\right)=\exp \left\{-\left(\frac{a_{j}-m_{j}^{(2)}}{\beta_{j}}\right)^{2}\right\} .
$$

The estimation of the parameters of the relations (9) is carried out by the least squares method independently for the left and right branches of the membership function (9). Let us introduce the quality criteria for the approximation:

$$
\begin{aligned}
& J_{1}=\sum_{s=1}^{p}\left[\exp \left\{-\left(\frac{m_{j}^{(1)}-a_{j s}^{(1)}}{\alpha_{j}}\right)^{2}\right\}-\hat{\kappa}\left(a_{j s}^{(1)}\right)\right]^{2}, \\
& J_{2}=\sum_{s=1}^{p}\left[\exp \left\{-\left(\frac{a_{j s}^{(2)}-m_{j}^{(2)}}{\beta_{j}}\right)^{2}\right\}-\hat{\kappa}\left(a_{j s}^{(2)}\right)\right]^{2} .
\end{aligned}
$$

The task is in finding the values of the parameters $\left(m_{j}^{(1)}, \alpha_{j}\right)$ and $\left(m_{j}^{(2)}, \beta_{j}\right)$, minimizing respectively $J_{1}$ and $J_{2}$. In order to simplify the solution procedure, let us implement monotonic transformations over the components of relations (10) that do not distort the optimizing set. Wherein

$$
\begin{aligned}
J_{1} & \sim \sum_{s=1}^{p}\left[-\left(\frac{m_{j}^{(1)}-a_{j s}^{(1)}}{\alpha_{j}}\right)^{2}-\ln \left(\hat{\kappa}\left(a_{j s}^{(1)}\right)\right)\right]^{2}=\sum_{s=1}^{p}\left[\left(\frac{m_{j}^{(1)}-a_{j s}^{(1)}}{\alpha_{j}}\right)^{2}-\ln \left(\frac{1}{\hat{\kappa}\left(a_{j s}^{(1)}\right)}\right)\right]^{2} \\
& \sim \sum_{s=1}^{p}\left[\frac{m_{j}^{(1)}-a_{j s}^{(1)}}{\alpha_{j}}-\frac{1}{2} \ln \frac{1}{\hat{\kappa}\left(a_{j s}^{(1)}\right)}\right]^{2}=\sum_{s=1}^{p}\left(m_{j}^{(1)}-a_{j s}^{(1)}-\alpha_{j} l_{j s}^{(1)}\right)^{2}, \quad l_{j s}^{(1)}=\frac{1}{2} \ln \frac{1}{\hat{\kappa}\left(a_{j s}^{(1)}\right)} .
\end{aligned}
$$

Similarly

$$
\begin{aligned}
J_{2} & \sim \sum_{s=1}^{p}\left[-\left(\frac{a_{j s}^{(2)}-m_{j}^{(2)}}{\beta_{j}}\right)^{2}-\ln \left(\hat{\kappa}\left(a_{j s}^{(2)}\right)\right)\right]^{2} \sim \sum_{s=1}^{p}\left[\frac{a_{j s}^{(2)}-m_{j}^{(2)}}{\beta_{j}}-\frac{1}{2} \ln \frac{1}{\hat{\kappa}\left(a_{j s}^{(2)}\right)}\right]^{2} \\
& \sim \sum_{s=1}^{p}\left(m_{j}^{(2)}-a_{j s}^{(2)}-\beta_{j} l_{j s}^{(2)}\right)^{2} .
\end{aligned}
$$

Using (11), let us obtain the parameter estimates $m_{j}^{(1)}$ and $a_{j}$ :

$$
\begin{aligned}
\frac{d J_{1}}{d m_{j}^{(1)}} & =2 \sum_{s=1}^{p}\left(m_{j}^{(1)}-a_{j s}^{(1)}-\alpha_{j} l_{j s}^{(1)}\right)=0, \\
\frac{d J_{1}}{d \alpha_{j}} & =2 \sum_{s=1}^{p}\left(m_{j}^{(1)}-a_{j s}^{(1)}-\alpha_{j} l_{j s}^{(1)}\right)\left(-l_{j s}^{(1)}\right)=0 .
\end{aligned}
$$

So

$$
\left\{\begin{array}{l}
p m_{j}^{(1)}-\alpha_{j} \sum_{s=1}^{p} l_{j s}^{(1)}=\sum_{s=1}^{p} a_{j s}^{(1)}, \\
m_{j}^{(1)} \sum_{s=1}^{p} l_{j s}^{(1)}-\alpha_{j} \sum_{s=1}^{p}\left(l_{j s}^{(1)}\right)^{2}=\sum_{s=1}^{p} a_{j s}^{(1)} l_{j s}^{(1)} .
\end{array}\right.
$$


The system of linear algebraic equations (13) gives the desired estimates:

$$
\begin{aligned}
& m_{j}^{(1)}= \frac{-\left(\sum_{s=1}^{p} a_{j s}^{(1)}\right)\left(\sum_{s=1}^{p}\left(l_{j s}^{(1)}\right)^{2}+\left(\sum_{s=1}^{p} l_{j s}^{(1)}\right)\left(\sum_{s=1}^{p} a_{j s}^{(1)} l_{j s}^{(1)}\right)\right)}{-p \sum_{s=1}^{p}\left(l_{j s}^{(1)}\right)^{2}+\left(\sum_{s=1}^{p} l_{j s}^{(1)}\right)^{2}}, \\
& \alpha_{j}=\frac{-p\left(\sum_{s=1}^{p} a_{j s}^{(1)} l_{j s}^{(1)}\right)+\left(\sum_{s=1}^{p} l_{j s}^{(1)}\right)\left(\sum_{s=1}^{p} a_{j s}^{(1)}\right)}{-p \sum_{s=1}^{p}\left(l_{j s}^{(1)}\right)^{2}+\left(\sum_{s=1}^{p} l_{j s}^{(1)}\right)^{2}}
\end{aligned}
$$

Similarly, using (12), let us obtain the estimates of the values $m_{j}^{(2)}$ and $\beta_{j}$ :

$$
\begin{aligned}
\frac{d J_{2}}{d m_{j}^{(2)}} & =-2 \sum_{s=1}^{p}\left(a_{j s}^{(2)}-m_{j}^{(2)}-\beta_{j} l_{j s}^{(2)}\right)=0, \\
\frac{d J_{2}}{d \beta_{j}} & =2 \sum_{s=1}^{p}\left(a_{j s}^{(2)}-m_{j}^{(2)}-\beta_{j} l_{j s}^{(2)}\right)\left(-l_{j s}^{(2)}\right)=0 .
\end{aligned}
$$

So

$$
\left\{\begin{array}{l}
p m_{j}^{(2)}+\beta_{j} \sum_{s=1}^{p} l_{j s}^{(2)}=\sum_{s=1}^{p} a_{j s}^{(2)}, \\
m_{j}^{(2)} \sum_{s=1}^{p} l_{j s}^{(2)}+\beta_{j} \sum_{s=1}^{p}\left(l_{j s}^{(2)}\right)^{2}=\sum_{s=1}^{p} a_{j s}^{(2)} l_{j s}^{(2)} .
\end{array}\right.
$$

The system of linear algebraic equations (15) gives the desired estimates:

$$
\begin{gathered}
m_{j}^{(2)}=\frac{\left(\sum_{s=1}^{p} a_{j s}^{(2)}\right)\left(\sum_{s=1}^{p}\left(l_{j s}^{(2)}\right)^{2}+\left(\sum_{s=1}^{p} l_{j s}^{(2)}\right)\left(\sum_{s=1}^{p} a_{j s}^{(2)} l_{j s}^{(2)}\right)\right)}{-p \sum_{s=1}^{p}\left(l_{j s}^{(2)}\right)^{2}+\left(\sum_{s=1}^{p} l_{j s}^{(2)}\right)^{2}} \\
\beta_{j}=\frac{p\left(\sum_{s=1}^{p} a_{j s}^{(2)} l_{j s}^{(2)}\right)+\left(\sum_{s=1}^{p} l_{j s}^{(2)}\right)\left(\sum_{s=1}^{p} a_{j s}^{(2)}\right)}{-p \sum_{s=1}^{p}\left(l_{j s}^{(2)}\right)^{2}+\left(\sum_{s=1}^{p} l_{j s}^{(2)}\right)^{2}}
\end{gathered}
$$

The obtained relations (14), (16) give the exact mean-square values of the parameter estimates for the membership functions of fuzzy numbers, which determine the importance of the particular criteria for the quality of objects. At the same time, approximate estimates of the values of these parameters can be easily obtained on the basis of the accepted Gaussian character of the membership functions (L-R)-type [6]. Wherein

$$
m_{j}^{(1)}=\max _{s}\left(a_{j s}^{(1)}\right) ; \quad \alpha=\frac{\sqrt{2}}{3}\left(\max _{s}\left(a_{j s}^{(1)}\right)-\min _{s}\left(a_{j s}^{(1)}\right)\right) ;
$$




$$
m_{j}^{(2)}=\min _{s}\left(a_{j s}^{(2)}\right) ; \quad \beta=\frac{\sqrt{2}}{3}\left(\max _{s}\left(a_{j s}^{(2)}\right)-\min _{s}\left(a_{j s}^{(2)}\right)\right)
$$

In this example, taking into account the data from Table 1, 2, let us obtain

$$
\begin{array}{ll}
m_{j}^{(1)}=4.5 ; & \alpha=\frac{\sqrt{2}}{3}(4.5-1.7)=1.32 \\
m_{j}^{(2)}=5.4 ; & \beta=\frac{\sqrt{2}}{3}(9.7-5.4)=2.03
\end{array}
$$

Moreover, in practical calculations, the following even more radical simplification is considered permissible, due to the transition from the interval description of the membership function (L-R)-type to the usual one. At the same time

$$
\mu_{j}(a)=\left\{\begin{array}{l}
L\left(\frac{m_{j}-a_{j}}{\alpha_{j}}\right), a_{j} \leqslant m_{j}, \\
R\left(\frac{a_{j}-m_{j}}{\beta_{j}}\right), a_{j}>m_{j} .
\end{array}\right.
$$

Here

$$
\begin{aligned}
m_{j} & =\frac{1}{2}\left(\max _{s}\left(a_{j s}^{(1)}\right)+\min _{s}\left(a_{j s}^{(2)}\right)\right), \\
\alpha_{j} & =\frac{\sqrt{2}}{3}\left(m_{j}+\min _{s}\left(a_{j s}^{(1)}\right)\right), \\
\beta_{j} & =\frac{\sqrt{2}}{3}\left(\max _{s}\left(a_{j s}^{(2)}\right)-m_{j}\right) .
\end{aligned}
$$

Let us proceed to the solution of the second problem. It naturally splits into two subtasks:

2a) formation of an analytical description of the quality criterion, taking into account the ambiguity of the weighting coefficients of the importance of particular criteria;

$2 \mathrm{~b})$ development of a methodology for optimizing the criterion obtained.

Let us consider the situation when solving a multi-criteria optimization problem, an approach is chosen that is associated with the use of a scalar criterion. If the weights are fuzzy numbers with known membership functions, then the resulting scalar criterion will also be a fuzzy number. Let us describe the technology of formation of the membership function of the resulting scalar criterion. The technology is implemented according to the rules for performing operations on fuzzy numbers $[4,5,7,8]$. Let us present the main ones taking into account the fact that the unclearness of the weight coefficients is described by the membership functions (L-R)-type.

Let $A_{1}$ and $A_{2}$ be arbitrary positive fuzzy numbers of (L-R)-type given by their parameters $\left\langle m_{1}, \alpha_{1}, \beta_{1}\right\rangle,\left\langle m_{2}, \alpha_{2}, \beta_{2}\right\rangle$. The basic arithmetic operations on these numbers are performed as follows.

Addition: $A_{1}+A_{2}=B=\left\langle m_{B}, \alpha_{B}, \beta_{B}\right\rangle$, where $m_{B}=m_{1}+m_{2}, \alpha_{B}=\alpha_{1}+\alpha_{2}, \beta_{B}=\beta_{1}+\beta_{2}$.

Subtraction: $A_{1}-A_{2}=B=\left\langle m_{B}, \alpha_{B}, \beta_{B}\right\rangle$, where: $m_{B}=m_{1}-m_{2}, \alpha_{B}=\alpha_{1}+\alpha_{2}, \beta_{B}=\beta_{1}+\beta_{2}$.

Multiplication: $A_{1} \cdot A_{2}=B=\left\langle m_{B}, \alpha_{B}, \beta_{B}\right\rangle$, where $m_{B}=\alpha_{1} \cdot \alpha_{2}, \alpha_{B}=m_{1} \alpha_{2}+m_{2} \alpha_{1}+\alpha_{1} \alpha_{2}$, $\beta_{B}=m_{1} \beta_{2}+m_{2} \beta_{1}+\beta_{1} \beta_{2}$.

Division: $A_{1}: A_{2}=B=\left\langle m_{B}, \alpha_{B}, \beta_{B}\right\rangle$, where $m_{B}=m_{1} / m_{2}, \alpha_{B}=\frac{m_{1} \beta_{2}+m_{2} \alpha_{1}}{\alpha_{2}^{2}}, \beta_{B}=\frac{m_{1} \alpha_{2}+m_{2} \beta_{1}}{\alpha_{2}^{2}}$.

Subtask 2a. Using these relations, let us find the membership function of the fuzzy value of the scalar criterion.

$$
y=\sum_{j=1}^{n} a_{j} F_{j} .
$$


At the same time, taking into account (17)

$$
\mu\left(a_{j} F_{j}\right)=\mu\left(u_{j}\right)= \begin{cases}L\left(\frac{\bar{u}_{j}-u_{j}}{\alpha_{u_{j}}}\right), & u_{j} \leqslant \bar{u}_{j}, \\ R\left(\frac{u_{j}-\bar{u}_{j}}{\beta_{u_{j}}}\right), & u_{j}>\bar{u}_{j} .\end{cases}
$$

Where $\bar{u}_{j}=m_{j} F_{j} ; \alpha_{u_{j}}=F_{j} \alpha_{j} ; \beta_{u_{j}}=F_{j} \beta_{j}$.

Then

$$
\mu(y)=\mu\left(\sum_{j=1}^{n} a_{j} F_{j}\right)=\mu\left(\sum_{j=1}^{n} u_{j}\right)=\left\{\begin{array}{l}
L\left(\frac{\bar{y}-y}{\alpha_{y}}\right), y \leqslant \bar{y} \\
R\left(\frac{y-\bar{y}}{\beta_{y}}\right), y>\bar{y} .
\end{array}\right.
$$

where $\bar{y}=\sum_{j=1}^{n} \bar{u}_{j}=\sum_{j=1}^{n} m_{j} F_{j} ; \alpha_{y}=\sum_{j=1}^{n} \alpha_{u_{j}}=\sum_{j=1}^{n} F_{j} \alpha_{j} ; \beta_{y}=\sum_{j=1}^{n} \beta_{u_{j}}=\sum_{j=1}^{n} F_{j} \beta_{j}$.

Thus, the membership function of the fuzzy value of the scalar criterion is obtained.

Subtask 2b. Let us consider a solution technique on a simple example. Let, in order to ensure the proper quality of the functioning of the system, some resource $\mathrm{R}$ is allocated, which is spent to maintain the proper quality of the system for each of the criteria. Let us introduce $A_{j}$ is a measure of improving the quality of the system according to the $j$-th criterion when spending a unit of resource $j=1,2, \ldots, n, a_{j}$ is importance of criterion, $j=1,2, \ldots, n ; x_{j}$ is the number of resource units planned to improve the system according to the $\mathrm{j}$-th criterion $j=1,2, \ldots, n$.

Then the plan $X=\left(x_{1}, x_{2}, \ldots, x_{n}\right)$ corresponds to improving the quality of the system by

$$
G(X)=\sum_{j=1}^{n} a_{j} F_{j}=\sum_{j=1}^{n} a_{j} c_{j} x_{j} .
$$

The plan $X$ must meet the limit on the total consumption of the resource.

$$
\sum_{j=1}^{n} x_{j}=R
$$

The task of finding a plan $X$ that maximizes (19) and satisfies (20) is the simplest linear programming problem $[9,10]$ and for a well-defined set $\left\{a_{j}\right\}$ has a trivial solution:

$$
x_{j}=0, \quad j \neq j_{0}, \quad j_{0}=\underset{j}{\arg \max }\left\{a_{j} c_{j}\right\}, \quad x_{j_{0}}=R .
$$

The task becomes much more complicated if $a_{j}$ are fuzzy numbers.

A possible approach to solving the problem of resource allocation in this case is as follows.

Let a fuzzy number $z$ have a membership function $\mu(z)$. Let us introduce a new function [11]

$$
\varphi(z)=\frac{\mu(z)}{\int_{-\infty}^{\infty} \mu(z) d z} .
$$

This function (if the integral in the denominator converges) has an important feature - the integral of it by $z$ is equal to 1 . Thus, this non-negative and normalized function $\varphi(z)$ satisfies the requirements for the distribution density of random variables. In this regard, the value $z$ can be interpreted as random with the distribution density $\varphi(z)$. Then it is possible to calculate the probability that this random variable $z$ will take a value that exceeds the threshold value. $z_{n}$ This probability is equal to

$$
P\left(z>z_{n}\right)=\int_{z_{n}}^{\infty} \varphi(z) d z .
$$


Let us use the introduced transformation (21) for a fuzzy number $G(X)$ and find the membership function of a fuzzy number (19).

If the fuzzy value of the scalar criterion is given by the membership function (L-R)-type with a Gaussian analytical description (9), then in accordance with the rules for performing operations on fuzzy numbers, let us have

$$
\mu(x)= \begin{cases}\exp \left\{-\left(\frac{\bar{G}-G}{\alpha_{G}}\right)^{2}\right\}, & G \leqslant \bar{G}, \\ \exp \left\{-\left(\frac{G-\bar{G}}{\beta_{G}}\right)^{2}\right\}, & G>\bar{G}\end{cases}
$$

where $\bar{G}=\sum_{j=1}^{n} m_{j} c_{j} x_{j}, \alpha_{G}=\sum_{j=1}^{n} \alpha_{j} c_{j} x_{j}, \beta_{G}=\sum_{j=1}^{n} \beta_{j} c_{j} x_{j}$.

Let us calculate

$$
\begin{aligned}
\int_{-\infty}^{\infty} \mu(G) d G & =\int_{-\infty}^{\bar{G}} \exp \left\{-\left(\frac{\bar{G}-G}{\alpha_{G}}\right)^{2}\right\} d G+\int_{\bar{G}}^{\infty} \exp \left\{-\left(\frac{G-\bar{G}}{\beta_{G}}\right)^{2}\right\} d G \\
= & \sqrt{2 \pi}\left(\frac{\alpha_{G}}{\sqrt{2}}\right) \int_{-\infty}^{\bar{G}} \frac{1}{\sqrt{2 \pi}\left(\frac{\alpha_{G}}{\sqrt{2}}\right)} \exp \left\{-\frac{(\bar{G}-G)^{2}}{2\left(\frac{\alpha_{G}}{\sqrt{2}}\right)^{2}}\right\} d G \\
& +\sqrt{2 \pi}\left(\frac{\beta_{G}}{\sqrt{2}}\right) \int_{\bar{G}}^{\infty} \frac{1}{\sqrt{2 \pi}\left(\frac{\beta_{G}}{\sqrt{2}}\right)} \exp \left\{-\frac{(G-\bar{G})^{2}}{2\left(\frac{\beta_{G}}{\sqrt{2}}\right)^{2}}\right\} d G=\frac{\sqrt{\pi}\left(\alpha_{G}+\beta_{G}\right)}{2} .
\end{aligned}
$$

At the same time $\varphi(G)=\frac{2 \mu(G)}{\sqrt{\pi}\left(\alpha_{G}+\beta_{G}\right)}$ is the distribution density $G$. Then the probability that $G$ exceeds the threshold value $G_{n},\left(G_{n} \geqslant \bar{G}\right)$ will be equal to

$$
\begin{aligned}
P\left(G \geqslant G_{n}\right) & =\frac{2}{\sqrt{\pi}\left(\alpha_{G}+\beta_{G}\right)} \int_{G_{n}}^{\infty} \exp \left\{-\left(\frac{(G-\bar{G})}{\beta_{G}}\right)^{2}\right\} d G \\
& =\frac{2 \beta_{G}}{\alpha_{G}+\beta_{G}} \int_{\frac{G_{n}-\bar{G}}{\beta} \sqrt{2}}^{\infty} \frac{1}{\sqrt{2 \pi}} e^{-\frac{u^{2}}{2}} d u, \quad u=\frac{G-\bar{G}}{\beta_{G}} \sqrt{2} ; \quad u=\frac{G-\bar{G}}{\beta_{G}} \sqrt{2} .
\end{aligned}
$$

Thus, the problem of rational distribution of a limited resource is reduced to finding a plan $X$ that maximizes (22) and satisfies (20). It is clear that maximizing (22) is equivalent to minimizing the lower limit in this integral.

Since $\bar{G}=\sum_{j=1}^{n} m_{j} F_{j}=\sum_{j=1}^{n} m_{j} c_{j} x_{j}, \beta_{G}=\sum_{j=1}^{n} \beta_{j} F_{j}=\sum_{j=1}^{n} \beta_{j} c_{j} x_{j}$, then the non-trivial problem of fractional-linear mathematical programming arises. To solve it, let us use the following approach.

The mathematical model of a fractional-linear programming problem is: find a set $X=$ $\left(X_{1}, X_{2}, \ldots, X_{n}\right)$ minimizing

$$
\Phi(X)=\frac{\sum_{j=1}^{n} c_{j} x_{j}}{\sum_{j=1}^{n} d_{j} x_{j}}
$$


and satisfying the constraint system

$$
\begin{array}{ll}
\sum_{j=1}^{n} a_{i j} x_{j}=b_{i}, & i=1,2, \ldots, m, \\
x_{j} \geqslant 0, & j=1,2, \ldots, n,
\end{array}
$$

the denominator in (23) does not change the sign (for example, $\alpha_{j} \geqslant 0, j=1,2, \ldots, n$ ).

Let us introduce a new variable

$$
y_{0}=\frac{1}{\sum_{j=1}^{n} d_{j} x_{j}},
$$

as well as new variables

$$
y_{j}=y_{0} x_{j}, \quad x_{j}=\frac{y_{j}}{y_{0}}, \quad j=1,2, \ldots, n .
$$

Then (23)-(25) are converted to the form:

$$
\begin{gathered}
\frac{\sum_{j=1}^{n} c_{j} x_{j}}{\sum_{j=1}^{n} d_{j} x_{j}}=y_{0} \sum_{j=1}^{n} c_{j} x_{j}=\sum_{j=1}^{n} c_{j} y_{j}, \\
\sum_{j=1}^{n} a_{i j} x_{j}=\frac{1}{y_{0}} \sum_{j=1}^{n} a_{i j} y_{j}=b_{i}, \quad i=1,2, \ldots, m,
\end{gathered}
$$

SO

$$
\sum_{j=1}^{n} a_{i j} y_{j}=y_{0} b_{i}, \quad i=1,2, \ldots, m,
$$

and

$$
y_{0} \sum_{j=1}^{n} d_{j} x_{j}=\sum_{j=1}^{n} d_{j} y_{j}=1 .
$$

Thus, the original problem $(23)-(25)$ is reduced to the following: find a set $\left(y_{0}, y_{2}, \ldots, y_{n}\right)$ that minimizes (27) and satisfies constraints (28), (29). The usual linear programming problem is obtained. Let the set $\left(y_{0}^{*}, y_{1}^{*}, \ldots, y_{n}^{*}\right)$ is the solution to this problem. Then, using (26), let us obtain the solution of the original problem

$$
x_{j}^{*}=\frac{y_{j}^{*}}{y_{0}^{*}}, \quad j=1,2, \ldots, n .
$$

Let us now consider the situation when, when solving a multi-criteria optimization problem, on the set of points corresponding to the values of the partial criteria for different system building options, a Pareto-set of non-majorized options is formed. The selection of these non-majorized options is associated with the operation of comparing the values of the criteria for all pairs of competing options. If the values of the criteria are not clearly defined by their membership functions, then this operation is easily implemented using the transformation (21) of the membership functions to the corresponding distribution density.

Let a pair of fuzzy numbers $z_{1}$ and $z_{2}$ membership functions $\mu_{1}\left(z_{1}\right)$ and $\mu_{2}\left(z_{2}\right)$ correspond to the density of distribution

$$
\varphi_{1}\left(z_{1}\right)=\frac{\mu_{1}\left(z_{1}\right)}{\int_{-\infty}^{\infty} \mu_{1}\left(z_{1}\right) d z_{1}}, \quad \varphi_{2}\left(z_{2}\right)=\frac{\mu_{2}\left(z_{2}\right)}{\int_{-\infty}^{\infty} \mu_{2}\left(z_{2}\right) d z_{2}} .
$$


Then for comparison $z_{1}$ and $z_{2}$ let us calculate the probability that $z_{1} \geqslant z_{2}$ according to the formula

$$
P\left(z_{1} \geqslant z_{2}\right)=\int_{0}^{\infty}\left(\int_{0}^{z_{1}} \varphi_{2}\left(z_{2}\right) d z_{2}\right) \varphi_{1}\left(z_{1}\right) d z_{1} .
$$

Now let us assume that $z_{1} \geqslant z_{2}$ if the numerical value of the integral (30) is greater than 0.5.

Let us suppose that in a multi-criteria problem of choosing a option for constructing a system a certain set of options $\left\{A_{1}, A_{2}, \ldots, A_{q}, \ldots, A_{Q}\right\}$ is given. Option $A_{q}$ corresponds to a set $\left\{F_{q_{1}}, F_{q_{2}}, \ldots, F_{q_{n}}\right\}$ of fuzzy specified criteria values. Then the option $A_{q_{1}}$ majorizes the option $A_{q_{2}}$ if $F_{q_{1} j} \geqslant F_{q_{2} j}$, $j=1,2, \ldots, n$, that is, $P\left(F_{q_{1} j} \geqslant F_{q_{2} j}\right)>0.5, j=1,2, \ldots, n$.

Finally, let us consider the peculiarity of the technology for solving the problem of multi-criteria optimization for the case when the main criterion is selected from a set of criteria. This criterion is optimized, and the rest are used as constraints. If at the same time, the coefficients that determine the importance of the criteria are not clearly defined, then the main one is determined using the comparison procedure (30).

\section{Discussion of the results}

For the problem of multi-criteria optimization, possible ways of its solution are considered: scalarization of the vector criterion; the formation of a Pareto-set of non-majorized options; selection of the main criteria, taking into account the rest, as constraints. Methods are proposed for implementing these approaches for the case when coefficients that take into account differences in the importance of criteria are described in terms of fuzzy mathematics.

In this case, if fuzzy weights are given by sets of intervals of possible values, a method for calculating the corresponding membership functions is proposed. The fuzzy multi-criteria optimization problem obtained in this case is reduced to a linear-fractional problem of mathematical programming. A method for its solution is proposed.

A possible approach to solving the original problem using the method of forming a Pareto-set of options, as well as a method for solving this problem in the case when it is expedient to choose the main criterion with the other criteria as constraints, is considered.

The study of the problem of multi-criteria optimization should be continued in the following directions. Further development can be obtained by the method of processing the initial data on the values of weights, taking into account the relative importance of the criteria. If these data are determined by sets of intervals, the left and right boundaries of which are not clearly defined or inaccurate, then their correct description can be performed by appropriate methods [3-5,12-14]. In addition, for solving a multi-criteria optimization problem, the methods proposed in [15], alternative to the one described above, can be used. Comparison of the effectiveness of these methods is of theoretical and practical interest.

\section{Conclusions}

1. Known methods for solving a multi-criteria optimization problem are generalized to the case when the coefficients that take into account the importance of particular criteria are not clearly defined.

2. A method is proposed for solving a fuzzy multi-criteria optimization problem for a scalarized criterion, leading to a linear-fractional mathematical programming problem.

3. A method for solving the obtained fuzzy problem, based on the formation of a Pareto-set of nondominated options, is considered.

[1] Saaty T. L. Mathematical Methods of Operations Research. McGraw-Hill (1959).

Mathematical Modeling and Computing, Vol. 5, No. 2, pp. 207-220 (2018) 
[2] Seraja O. V. Mnogomernye modeli logistiki v uslovijah neopredelennosti. Harkiv, FOP Stecenko (2010), (in Russian).

[3] Zadeh L. A. Fuzzy Sets. Information and Control. 8 (3), 338-353 (1965).

[4] Kaufmann A. Introduction a la théorie des sous-ensembles flous. Paris, New York, Barcelone, Milan, MASSON (1977), (in French).

[5] Raskin L. G., Seraja O. V. Nechetkaja matematika. Osnovy teorii. Prilozhenija. Harkiv, Parus (2008), (in Russian).

[6] Ventcel E. S. Teorija verojatnostej : uchebnik. Moskva, KNORUS (2010), (in Russian).

[7] Dubois D., Prade H. Théorie des possibilités. Applications à la représentation des connaissances en informatique. Paris, Milan, Barcelona, Mexico, MASSON (1988), (in French).

[8] Leonenkov A. V. Nechetkoe modelirovanie v srede MATLAB i fuzzyTECH. SPb., BHV-Peterburg (2005), (in Russian).

[9] Dantzig G. B. Linear programming and extensions. Princeton, New Jersey, PRINCETON UNIVERSITY PRESS (1963).

[10] Yudin D. B., Golshtejn E. G. Linejnoe programmirovanie: teorija, metody i prilozhenija. Moskva, Nauka (1969), (in Rusiian).

[11] Liu B. Theory and Practice of Uncertain Programming. Heidelberg, Physica-Verlag (2002).

[12] Pawlak Z. Rough Sets and Fuzzy Sets. Fuzzy Sets and Systems. 17 (1), 99-102 (1985).

[13] Raskin L., Sira O. Fuzzy models of rough mathematics. Eastern-European Journal of Enterprise Technologies. 6 (4), 53-60 (2016), (in Russian).

[14] Sira O. V., Al-Shqeerat K. H. A New Approach for Resolving Equations with Fuzzy Parameters. European Journal of Scientific Research. 38 (4), 619-625 (2009).

[15] Raskin L., Sira O. Method of solving fuzzy problems of mathematical programming. Eastern-European Journal of Enterprise Technologies. 5 (4), 23-28 (2016), (in Russian). 


\title{
Багатокритеріальна оптимізація в умовах нечітко визначених важливостей критеріїв
}

\author{
Раскін Л., Сіра О., Сагайдачний Д. \\ Національний технічний університет "Харківсъкий політехнічний інститут", \\ вул. Кірпічова, 2, Харків, 61000, Україна
}

Розглянуто задачі багатокритеріальної оптимізації. Відомі методи розв'язання цих задач узагальнено на випадок, коли вагові коефіцієнти, що враховують відносну важливість окремих критеріїв, визначені нечітко. Обгрунтовано процедуру побудови функцій приналежності нечітких чисел, заданих наборами інтервалів можливих значень, що використовуе лінеаризовану обчислювальну схему методу найменших квадратів. Для описів нечітких чисел вибрано функції приналежності (L-R)-типу.

Запропоновано метод розв'язування нечіткої задачі багатокритеріальної оптимізації для скаляризованого критерію. Технологія розв'язування задачі зводить іï до дробово-нелінійної задачі математичного програмування. Описано збіжну ітераційну процедуру знаходження оптимального плану.

Розглянуто альтернативний метод розв'язування нечіткої задачі на основі формування Парето-множини недомінуючих варіантів. Для розв'язання цієї задачі запропоновано процедуру порівняння нечітких чисел з використанням теоретико-ймовірнісної апроксимації їх функцій приналежності.

Ключові слова: багатокритеріальна оптимізачіл, нечіткі вихідні дані, оптимізачія дробово-нелінійного функціонала, Парето-множина.

2000 MSC: 90B99

Удк: 519.856 .2 